\title{
PERANAN ECONOMIC ORDER QUANTITY DALAM PENINGKATAN EFISIENSI PENGELOLAAN PERSEDIAAN PADA PT. MARTINA BERTO Tbk.
}

\author{
Ono Tarsono $^{1}$, Siti Khotimah ${ }^{2}$ \\ Sekolah Tinggi Ilmu Ekonomi Indonesia \\ Jalan Kayu Jati Raya No 11A, Jakarta 13220, Indonesia \\ masonokece@gmail.com ${ }^{1}$, skhotimah88@gmail.com $^{2}$
}

\begin{abstract}
Abstrak - Penelitian ini bertujuan untuk (1) mengetahui jumlah safety stock yang sudah ditetapkan oleh manajemen perusahaan apakah sudah optimal (2) mengetahui jumlah pembelian bahan baku yang optimal, dan mengetahui total biaya persediaan yang optimal, dan (3) mengetahui waktu pemesanan kembali (reorder point). Data yang dipelajari berupa data tentang (1) kebutuhan bahan baku tahun 2015 (2) biaya pemesanan setiap kali pesan tahun 2015 (3) harga faktur bahan yang dibeli tahun 2015 (4) biaya penyimpanan variabel tahun 2015.

Metode penelitiaan yang digunakan adalah (1) Metode Economic Order Quantity (EOQ) (2) Metode Safety Stock (SS) (3) Metode Reorder Point (ROP). Dengan diperoleh kesimpulan sebagai berikut : (1) Besarnya safety stock ditentukan oleh perusahaan sebesar 30\% dari kebutuhan bulan berikutnya (2) Kuantitas pembelian optimal bahan baku alcohol sebesar 15,6 ton, dengan frekuensi pembelian sebanyak 12 kali, bahan baku Texapon N-70 sebesar 10 ton, dengan frekuensi pembelian sebanyak 8 kali, bahan baku Whimol 15 sebesar 9 ton, dengan frekuensi pembelian sebanyak 7 kali, bahan baku Euperlan PK771 sebesar 7 ton, dengan frekuensi pembelian sebanyak 5 kali, dan bahan baku Edenor C12-99 MY sebesar 7 ton, dengan frekuensi pembelian sebanyak 5 kali, dan besarnya total biaya persediaan untuk 5 (lima) jenis bahan baku utama sebesar 3.708.967.727. (3) Titik pemesanan kembali untuk bahan baku alcohol dilakukan apabila mencapai 14 ton, bahan baku Texapon mencapai 5.8 ton, bahan baku Whimol 15 mencapai 4.6 ton, bahan baku Euperlan PK771 mencapai 2.3 ton, dan bahan baku Edenor C12-99 MY mencapai 3.35 ton. Berdasarkan kesimpulan diatas, maka penulis memberikan saran kepada perusahaan PT. Martina Berto Tbk. Agar mempertimbangkan penggunaan metode EOQ dan kapan perusahaan harus melakukan pemesanan kembali, agar pengendalian persediaan yang efektif dan efisien dapat tercapai.
\end{abstract}

Kata Kunci :Economic Order Quantity (EOQ), Persediaan Bahan Baku, Reorder Point (ROP)

\section{PENDAHULUAN}

Perkembangan dunia usaha di Indonesia beberapa dekade belakangan ini tumbuh dengan pesat sejalan dengan kebijakan pemerintah baik kebijakan moneter maupun kebijakan fiskal yang dapat mendorong pertumbuhan disektor industry, maka persaingan antar perusahaan khususnya yang sejenis semakin meningkat. Kelangsungan hidup perusahaan dalam menghadapi persaingan yang ketat tersebut, diperlukan penanganan dan pengelolaan yang baik. Penanganan dan pengelolaan yang baik tersebut hanya dapat dilakukan oleh manajemen yang profesional. Manajemen dituntut untuk dapat mengkoordinasikan penggunaan seluruh sumber daya yang dimiliki perusahaan secara efektif dan efisien. Manajemen juga dituntut untuk dapat menghasilkan keputusan yang dapat menunjang pencapaian tujuan perusahaan. 
Manajemen hendaknya berpikir kritis dalam mengambil setiap keputusan, agar keputusan yang diambil dapat memberikan dampak yang baik bagi perkembangan perusahaan sehingga mampu mengantisipasi situasi persaingan pasar yang semakin meningkat.

Pembelian salah satu fungsi penting dalam menunjang keberhasilan bagian produksi perusahaan, karena fungsi ini mempunyai tanggung jawab untuk mendapatkan bahan baku dengan kuantitas dan kualitas yang baik dan sesuai kebutuhan, harga yang layak, penyerahan tepat waktu yang sesuai dengan ketentuan. Sebelum melakukan pembelian dibutuhkan adanya suatu strategi pembelian yang tepat bagi perusahaan untuk mendapatkan kuantitas dan kualitas bahan dan harga yang pantas. Strategi pembelian yang digunakan oleh setiap perusahaan berbeda-beda tergantung pada situasi yang dihadapi dan perkembangan usaha perusahaan. Sistem penyediaan bahan dengan strategi pembelian yang tepat dapat menjamin kelancaran kegiatan dan perkembangan perusahaan di masa yang akan datang. Oleh karena itu perlu pertimbangan yang cermat dan tepat agar setiap rencana yang hendak dilaksanakan dapat terealisasikan seperti apa yang diharapkan dan kemungkinan faktor-faktor yang menghambat dan mempercepat kedatangan barang perlu diantisipasi sedini mungkin.

Biaya pembelian material pada perusahaan mencakup sejumlah biaya yang dikeluarkan perusahaan untuk melaksanakan proses produksinya. Departemen pembelian harus mencari harga barang yang sesuai dengan standar kualitas yang ada dari beberapa supplier, sehingga departemen pembelian menghitung perkiraan harga material dengan memperhatikan harga standar pembelian bahan yang sudah ditetapkan perusahaan sebagai harga patokan, dengan demikian harga beli yang akan ditetapkan akan menjadi harga yang wajar. Pembelian material dengan harga terlalu mahal dari harga standar yang di tetapkan mengakibatkan peningkatan biaya produksi yang kemudian dapat mengurangi keuntungan perusahaan. Jika pembelian material dengan harga yang lebih rendah dari harga standar pembelian yang di tetapkan dengan standar kualitas pembelian yang telah ditetapkan, maka perusahaan dapat menerima dan mendapat keuntungan dari pembelian tersebut. Hal tersebut tentunya tidak sering muncul dalam departemen pembelian.

Hasil produksi perusahaan dipengaruhi oleh biaya produksi yaitu biaya bahan baku, biaya tenaga kerja, biaya overhead perusahaan yang di keluarkan perusahaan. Pengadaan bahan baku yang memegang peran penting bagi kelangsungan hidup perusahaan, dengan adanya bahan baku yang cukup memudahkan perusahaan menjalankan operasinya. Pembelian bahan baku yang terlalu besar akan menimbulkan risiko kerusakan seperti bertumpuknya barang di gudang, penurunan kualitas dan bertambahnya biaya penyimpanan. Sebaliknya jika pembelian bahan baku terlalu kecil akan menimbulkan risiko terlambatnya proses produksi dan timbulnya biaya tambahan pemesanan untuk mencari bahan baku pengganti. Selain itu waktu pembelian bahan baku juga harus di perhatikan seperti Lead Time yaitu waktu yang diperlukan untuk memesan barang sampai barang tersebut siap digunakan dan Procurement Lead Time yaitu penggunaan bahan selama tenggang waktu (Lead Time) untuk mendapatkan barang, hal tersebut sangat mempengaruhi kelangsungan produksi.

PT Martina Berto Tbk merupakan perusahaan besar yang berkembang dan maju. Perusahaan ini bergerak dibidang manufaktur yang memproduksi kosmetik seperti perawatan rambut (hair care), perawatan kulit (skin care), dan perawatan tubuh (body care). Salah satu produk yang banyak diminati konsumen adalah Shampoo Hijab dengan tujuan pemasaran di dalam negeri dan di luar negeri. Perusahaan merencanakan menurunkan biaya produksinya, dengan cara meminimalisasi biaya 
pembelian material produksi shampoo hijab. Mengingat kondisi perekonomian saat ini sedang labil, perusahaan perlu menetapkan standar biaya produksi, biaya tenaga kerja, biaya bahan baku, biaya penyimpanan dan standar harga jual.

Penelitian yang bertemakan EOQ sangat banyak sekali misalnya salah satu penelitian Analisis Pengendalian Persediaan Bahan Baku dengan Metode EOQ pada Perusahaan Handuk Lumintu Di Klaten, akan tetapi dari berbagai contoh penelitian tentang EOQ yang saya baca kebanyakan peneliti hanya membahas satu bahan baku ssaja, sedangkan untuk penelitian yang saya akan uraiakan ada 5 (lima) bahan baku yang akan saya paparkan.

Berdasarkan uraian tersebut di atas penulis tertarik untuk melakukan penelitian dengan mengambil topik Peranan Economic Order Quantity Dalam Peningkatan Efisiensi Pengelolaan Persediaan Pada PT. Martina Berto Tbk.

\section{KAJIAN PUSTAKA \\ Pengertian Bahan Baku}

Nasution (2003:103) menyatakan bahwa "bahan baku, yaitu yang merupakan input dari proses transformasi menjadi produk jadi. Cara membedakan apakah bahan baku termasuk bahan penolong dengan mengadakan penelusuran terhadap elemenelemen atau bahan-bahan ke dalam produk jadi. Cara pengadaan bahan baku bisa diperoleh dari sumber-sumber alam, petani atau membeli, misalnya serat diolah menjadi benang-benang".

Proses produksi suatu perusahaan manufaktur biasanya membutuhkan bahan baku untuk menghasilkan suatu produk. Carter Usry (2002:40) berpendapat bahwa ada dua macam jenis bahan baku yaitu :

a. Bahan baku langsung adalah semua bahan baku yang membentuk bagian integral dari produk jadi dan dimasukkan secara eksplisit dalam perhitungan biaya produk. Contoh dari bahan baku langsung adalah kayu yang digunakan untuk membuat mebel dan minyak mentah untuk membuat bensin.

b. Bahan baku tidak langsung adalah bahan baku yang diperlukan untuk meneyelesaikan suatu produk tetapi tidak diklasifikasikan sebagai bahan baku langsung karena bahan baku tersebut tidak menjadi bagian dari produk atau secara jumlah tidak siginifikan. Contoh nya adalah amplas pola kertas.

\section{Pengertian Pembelian Bahan Baku}

Carter (2009:303) menyatakan bahwa pembelian dalam perusahaan manufaktur, diartikan sebagai kegiatan yang dilakukan untuk mendapat bahan baku, bahan penolong, dan peralatan yang dibutuhkan dalam proses produksi. Pembelian bahan baku biasanya dilakukan oleh departemen pembelian dalam perusahaan besar dan dalam perusahaan yang lebih kecil, para kepala departemen atau penyelia memiliki wewenang untuk membeli bahan baku sesuai dengan kebutuhan.

\section{Economic Order Quantity}

Gitosudarmo (2002:101) menyatakan bahwa Economical Order Quantity (EOQ) merupakan volume atau jumlah pembelian yang paling ekonomis untuk dilaksanakan pada setiap kali pembelian. Begitu juga pendapat Hansen dan Mowen (2005 : 473). Mereka menyatakan bahwa, Economical Order Quantity (EOQ) atau kuantitas pesanan ekonomis adalah sebuah contoh dari sistem persediaan yang bertujuan menentukan kuantitas pesanan yang akan meminimalkan total biaya.

Gunawan Adisaputro (2014:220) menyatakan bahwa, hal yang perlu selalu dipikirkan oleh perusahaan selain besarnya kebutuhan juga besarnya (jumlah) bahan 
baku setiap kali dilakukan pembelian, yang menimbulkan biaya paling rendah tetapi tidak mengakibatkan kekurangan bahan baku. Jumlah yang paling ekonomis ini disebut sebagai Economical Order Quantity (EOQ). Dalam menghitung EOQ dipertimbangkan 2 (Dua) jenis biaya yang bersifat variable, yaitu:

a. Biaya Pemesanan (Ordering Costs)

b. Biaya Pemesanan yaitu biaya-biaya yang dikeluarkan sehubungan dengan kegiatan pemesanan bahan baku. Biaya ini berubah-ubah sesuai dengan frekuensi pemesanan, semakin tinggi frekuensi pemesanannya semakin tinggi pula biaya pemesanannya. Sebaliknya biaya ini berbanding terbalik dengan jumlah (kuantitas) bahan baku setiap kali pemesanan. Hal ini disebabkan karena semakin besarnya jumlah setiap kali pemesanan dilakukan, berarti frekuensi pemesanan menjadi semakin rendah.

c. Biaya Penyimpanan (Carrying Costs)

d. Biaya Penyimpanan yaitu biaya-biaya yang dikeluarkan sehubungan dengan kegiatan penyimpanan bahan baku yang telah dibeli. Biaya ini berubah-ubah sesuai dengan jumlah bahan baku yang disimpan. Semakin besar jumlah bahan baku setiap kali pemesanan maka biaya penyimpanan akan semakin besar pula. Jelaslah bahwa biaya penyimpanan mempunyai sifat yang berlawanan dengan biaya pemesanan.

Indra (2008:4) menyatakan bahwa Economical Order Quantity memiliki beberapa efisiensi sebagai berikut :

1) Jumlah barang yang dipesan pada setiap pemesanan selalu konstan.

2) Permintaan konsumen, biaya pemesanan, biaya transportasi, dan waktu antara pemesanan barang sampai dengan barang tersebut dikirim dapat diketahui secara pasti dan bersifat konstan.

3) Harga per unit barang konstan dan tidak memengaruhi jumlah barang yang akan dipesan nantinya.

4) Pada saat pemesanan barang tidak terjadi kehabisan barang atau back order yang menyebabkan perhitungan menjadi tidak tepat.

5) Biaya penyimpanan per unit per tahun konstan.

Berikut ini contoh grafik untuk menentukan besarnya kuantitas setiap kali pesanan yang paling ekonomis (EOQ) :

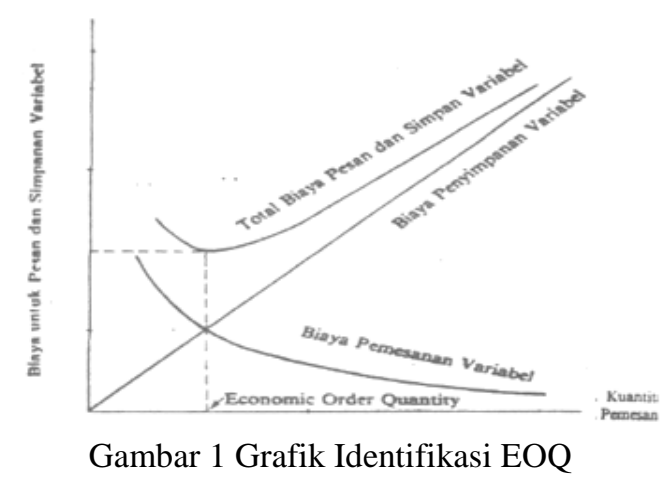

Berdasarkan grafik di atas, rumusan EOQ tersebut akan dapat digunakan dengan mudah dan praktis untuk merencanakan berapa kali suatu bahan di beli dan dalam kuantitas berapa setiap kali pembelian. 
Supriyono (1999:392) menayatakan bahwa, agar pemesanan variabel dan biaya penyimapanan variabel dapat ditekan serendah mungkin, dapat digunakan rumus Kuantitas Pesanan paling Ekonomis atau disebut Economic Order Quantity (EOQ) yang akan di uraikan sebagai berikut :

$$
E O Q=\sqrt{\frac{2 x R U x C O}{C U x C C}}
$$

Keterangan :

EOQ = Economic Order Quantity, kuantitas pesanan paling ekonomis (setiap kali pesan)

RU = Required unit for annual, kebutuhan bahan untuk tahun yang akan datang

$\mathrm{CO}=$ Cost per order, biaya pemesanan variable setiap kali pemesanan

$\mathrm{CU}=$ Cost per unit, harga faktur dan biaya angkut setiap satuan bahan yang di beli

$\mathrm{CC}=$ Carrying cost percentage, biaya penyimpanan variable yang dihitung berdasar persentase dari cost per unit bahan

Supriyono (1999:399) menyatakan bahwa, persediaan yang diselenggarakan paling banyak sebesar titik maksimum, yaitu pada saat bahan yang dibeli datang, tujuan penentuan titik maksimum agar dana yang tertanam pada persediaan bahan tdak berlebihan. Karena pada saat bahan yang dibeli datang besarnya bahan digudang sama dengan persediaan pengaman, maka setelah bahan yang dibeli dimasukkan pula kegudang, Sehingga dapat dirumuskan sebagai berikut :

$$
S S=M_{S}-E O Q
$$

Keterangan :

SS = Safety Stock, atau persediaan besi yang sekaligus merupakan minimum inventory point $(\mathrm{Mn})$ sesaat sebelum pembelian bahan datang

$\mathrm{M}_{\mathrm{s}}=$ Maximun inventory point, titik persediaan maksimum

EOQ = Economic Order Quantity, kuantitas pesanan paling ekonomis (setiap kali pesan)

Supriyono (1999:398) menyatakan bahwa, agar pembelian bahan baku yang sudah ditetapkan dalam EOQ tidak mengganggu kelancaran kegiatan produksi, maka perlu ditentukan waktu pemesanan kembali atas bahan yang paling tepat. Dapat disusunn rumus reorder point sebagai berikut :

$$
\begin{gathered}
R O P=(L T \times A U)+S S \\
P L T=L T \times A U
\end{gathered}
$$

Keterangan :

$\mathrm{ROP}=$ Re-order point, menunjukkan tingkat persediaan bahan di mana perusahaan harus memesan kembali

$\mathrm{PLT}=$ Procurement Lead Time, penggunaan selama tenggang waktu

LT = Lead Time, tenggang waktu antara pemesanan sampai kedatangan bahan

$\mathrm{AU}=$ Average usage, pemakaian rata-rata dalam satuan waktu tertentu

SS = Safety Stock, tingkat atau besarnya persediaan besi 
Carter (2009:319) menyatakan bahwa titik pemesanan kembali yang disebutnya sebagai reorder point adalah saat jumlah persediaan yang tersedia dan jumlah persediaan yang akan diterima sama dengan jumlah persediaan yang akan digunakan selama waktu tunggu dan jumlah persediaan pengaman.

Berdasarkan beberapa uraian tersebut terlampir contoh grafik yang menunjukkan titik maksimum dan minimum persediaan, serta reorder point dan EOQ.

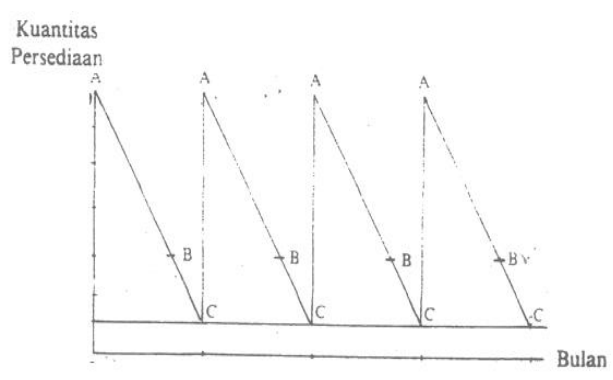

Gambar 2 Hubungan EOQ dengan Reorder Point dan Titik Maksimum Minimum

Nasution (2003:103) menyatakan bahwa persediaan adalah sumber daya menganggur (ide resource) yang menunggu proses lebih lanjut. Yang dimaksud dengan proses lebih lanjut tersebut adalah berupa kegiatan produksi pada sistem manufaktur, kegiatan pemasaran pada sistem distribusi ataupun kegiatan konsumsi pangan pada sistem rumah tangga.

\section{Pengertian Persediaan}

Nasution (2003:103) menyatakan bahwa persediaan adalah sumber daya menganggur (ide resource) yang menunggu proses lebih lanjut. Yang dimaksud dengan proses lebih lanjut tersebut adalah berupa kegiatan produksi pada sistem manufaktur, kegiatan pemasaran pada sistem distribusi ataupun kegiatan konsumsi pangan pada sistem rumah tangga.

\section{Fungsi Persediaan}

Fungsi-fungsi persediaan sebagaimana dikemukakan Rangkuti (1989:89) adalah sebagai berikut :

1) Fungsi Decoupling

2) Adalah persediaan yang memungkinkan perusahaan dapat memenuhi permintaan langganan tanpa tergantung supplier.

3) Fungsi Economic Lot Sizing

4) Persediaan ini perlu mempertimbangkan penghematan-penghematan atau potongan pembelian, biaya pengangkutan per unit menjadi lebih murah dan sebagainya. Dikarenakan perusahaan melakukan pembelian dalam kuantitas yang lebih besar, dibanding biaya-biaya yang timbul karena besarnya persediaan (biaya sewa gudang, investasi, resiko dan sebagainya).

5) Fungsi Antisipasi

6) Apabila perusahaan menghadapi fluktuasi permintaan yang dapat diramalkan berdasarkan data masa lalu, yaitu permintaan musiman (seasional inventories). Apabila keadaan musiman terjadi perusahaan dapat mengadakan permintaan musiman karena perusahaan juga sering menghadapi ketidakpastian jangka waktu pegiriman dan permintaan barang-barang selama 
periode tertentu, sehingga perusahaan memerlukan persediaan ekstra yang disebut persediaan pengaman (safety stock).

\section{Tujuan Pengendalian Persediaan}

Handoko (2000:359) berpendapat bahwa tujuan perusahaan menerapkan pengedalian persediaan adalah untuk:

1) Mengusahakan agar apa yang telah direncanakan bisa terjadi menjadi kenyataan.

2) Mengusahakan agar pelaksanaan pekerjaan sesuai dengan instruksi yang telah dikeluarkan.

3) Mengetahui kelemahan-kelemahan serta kesulitan-kesulitan yang dihadapi dalam pelaksanaan rencana.

Assauri (1999:177) menyatakan bahwa pengawasan persediaan bahan baku bertujuan untuk :

1) Menjaga agar jangan sampai perusahaan kehabisan persediaan yang dapat mengakibatkan terhentinya proses produksi.

2) Menjaga agar persediaan tidak berlebihan sehingga biaya yang ditimbulkan tidak menjadi lebih besar pula.

3) Menjaga agar pembelian secara kecil-kecilan dapat dihindari karena mengakibatkan biaya pemesanan yang tinggi.

Herjanto (1999:220) menyatakan bahwa pengendalian persediaan bertujuan untuk menentukan dan menjamin tersedianya persediaan yang tepat dalam kuantitas dan waktu yang tepat.

\section{Keputusan dalam Manajemen Persediaan}

Manajemen persediaan memerlukan perhatian yang penting dari pihak manajemen perusahaan karena manajemen yang buruk dapat menimbulkan masalah baik dalam kegiatan beroperasi maupun dalam bisnis.

Sudrajat (2010:1) dalam Prihasdi (2012:18) menyatakan bahwa dalam melaksanakan proses produksi, suatu perusahaan akan banyak menghadapi permasalahan yang kompleks, yang membutuhkan pengambilan keputusan yang tepat. Hal itu mengingat bahwa pengambilan keputusan bersifat futuristik, artinya bersangkut paut dengan hari depan, masa yang akan datang, di mana efek dan pengaruhnya berlangsung cukup lama.

\section{PROSEDUR PENELITIAN}

\section{Tempat dan Waktu Penelitian}

Penelitian ini bertempat di PT Martina Berto Tbk dengan alamat Jl. Pulo Kambing II No 1 Kawasan Industri Pulo Gadung Jakarta 13930. Waktu yang dibutuhkan untuk melakukan penelitian selama 5 (lima) bulan di mulai dari bulan Februari-Juni 2016.

\section{Strategi dan Metode Penelitian}

1) Strategi Penelitian

2) Strategi dalam penelitian ini adalah menggunakan strategi penelitian komparatif. Penelitian komparatif adalah penelitian yang dilakukan untuk 
membandingkan persamaan dan perbedaan dua atau lebih fakta-fakta dan sifat-sifat objek yang diteliti berdasarkan kerangka tertentu.

3) Metode penelitian

4) Metode yang digunakan dalam penelitian ini bersifat expost facto yaitu data yang dikumpulkan setelah peristiwa yang dipermasalahkan terjadi.

\section{Populasi dan Sampel}

Berdasarkan survey pendahulu di PT. Martina Berto Tbk. Diperoleh informasi untuk bahan baku yang digunakan sebanyak 1.463 jenis bahan baku. peneliti mengambil sampel sebanyak 5 (lima) jenis bahan baku utama saja seperti (Alcohol, Texapon N-70, Whimol 15, Euperlan PK771, dan Edenor C12-99 MY) ,karena bahan tersebut pemakaian nya dibanding bahan baku lain juauh lebih banyak.

\section{Jenis dan Sumber Data}

1) Jenis Data

Jenis data yang digunakan dalam penelitian ini meliputi data primer dan data sekunder. Data primer merupakan data yang diperoleh melalui interview dengan informan. Data sekunder yaitu data yang di peroleh dari berbagai literatur atau referensi yang dianggap relevan dengan penelitian ini

2) Sumber Data
a. Informan
b. Informasi pencatat data

\section{Teknik Pengumpulan Data}
a. Wawancara
b. Observasi
c. Studi Pustaka

\section{Metode Analisis Data}

Metode analisis data yaitu metode yang digunakan untuk membuat gambaran secara sistematis, faktual dan akurat mengenai suatu obyek yang akan diteliti. Metode analisis data yang digunakan adalah sebagai berikut :
a. Metode Economic Order Quantity (EOQ)
b. Metode Safety Stock (SS)
c. Metode Reorder Point (ROP)

\section{ANALISIS DATA DAN HASIL PENELITIAN}

\section{Analisis Metode EOQ}

Berdasarkan data-data yang sudah diinformasikan di atas maka langkah-langkah perhitungan dengan menggunakan metode Economic Order Quantity (EOQ) adalah sebagai berikut

1) Pembelian bahan baku yang Ekonomis (EOQ)

Hasil perhitungan EOQ dari masing-masing bahan utama dapat disajikan dalam tabel 1 berikut ini :

\section{Tabel 1}

Perhitungan EOQ Bahan Baku Utama Tahun 2015 


\begin{tabular}{|c|c|c|c|c|c|c|c|c|c|c|}
\hline No. & Kode Bahan & Nama Bahan & $\begin{array}{c}\text { Kebutuhan/ } \\
\text { Tahun }\end{array}$ & $\begin{array}{l}\text { Biaya Pesan } \\
\text { (CPO) }\end{array}$ & TOTAL & CPU/TON & CCPU & $\mathrm{CCP}$ & Total & EOQ \\
\hline (1) & (2) & (3) & (4) & (5) & $(6)=2 \times(\mid 4) \times(5)\}$ & (7) & (8) & (9) & $(10)=\mid(6) /(8)$ & $(11)=V(10)$ \\
\hline 1 & KALCO1 & ALCOHOL & 180 & Rp273.810 & Rp98.571.429 & Rp11.250.000 & Rp406.194 & $4 \%$ & 242,7 & 15,6 \\
\hline 2 & KTEX01 & TEXAPON N-70 & 81 & Rp273.810 & Rp44.357.143 & Rp27.995.000 & Rp406.194 & $1 \%$ & 109,2 & 10,4 \\
\hline 3 & KWHIO1 & WHOMOL 15 & 66 & Rp273.810 & Rp36.307.143 & Rp15.268.000 & Rp406.194 & $3 \%$ & 89,4 & 9,5 \\
\hline 4 & KEUPO1 & EUPERLAN PK 771 & 33 & Rp273.810 & Rp17.852.381 & Rp37.808.000 & Rp406.194 & $1 \%$ & 44,0 & 6,6 \\
\hline 5 & KAXA26 & $\begin{array}{l}\text { EDENOR C12-99 } \\
\text { MY }\end{array}$ & 34 & Rp273.810 & Rp18.619.048 & Rp24.730.000 & Rp406.194 & $2 \%$ & 45,8 & 6,8 \\
\hline & TOT & TAL & 393,9 & Rp1.369.048 & Rp215.707.143 & Rp117.051.000 & 406.194 & & 531 & 23,04 \\
\hline
\end{tabular}

Berdasarkan pada tabel di atas berikut maka Bahan Baku Utama Alcoho, hasil perhitungan untuk bahan baku alcohol dengan kebutuhan sebanyak 180 ton per tahun maka hasil pembelian bahan baku alcohol yang paling ekonomis (EOQ) sebesar 15.6 ton.

2) Frekuensi pemesanan bahan baku

Frekuensi pemesanan menurut metode EOQ dapat disajikan berikut ini:

Tabel 2

Frekuensi Pembelian Bahan Baku Utama Tahun 2015

\begin{tabular}{|c|c|c|c|c|c|c|}
\hline \multirow{2}{*}{ No. } & \multirow{2}{*}{$\begin{array}{l}\text { Kode } \\
\text { Bahan }\end{array}$} & \multirow{2}{*}{ Nama Bahan } & \multirow{2}{*}{$\begin{array}{c}\text { Kebutuhan } \\
\text { / Tahun }\end{array}$} & \multirow{2}{*}{ EOQ } & \multicolumn{2}{|c|}{ FPB } \\
\hline & & & & & Penelitian & Pembulatan \\
\hline (1) & (2) & (3) & (4) & (5) & & $(6)=(4) /(5)$ \\
\hline 1 & KALC01 & ALCOHOL & 180 & 15,6 & 11,6 & 12 \\
\hline 2 & KTEX01 & TEXAPON N-70 & 81 & 10,4 & 7,8 & 8 \\
\hline 3 & KWHIO1 & WHOMOL 15 & 66 & 9,5 & 7,0 & 7 \\
\hline 4 & KEUP01 & EUPERLAN PK 771 & 33 & 6,6 & 4,9 & 5 \\
\hline 5 & KAXA26 & EDENOR C12-99 MY & 34 & 6,8 & 5,0 & 5 \\
\hline \multicolumn{3}{|c|}{ TOTAL } & 393,9 & 19,85 & & \\
\hline
\end{tabular}

Bahan baku utama Alcohol, hasil perhitungan frekuensi pembelian untuk bahan baku alcohol dengan kebutuhan selama setahun sebesar 180 ton dan hasil pembelian yang paling ekonomis (EOQ) sebesar 15.5 ton, maka frekensi pembelian bahannya nya sebesar 12 kali dalam setahun.

1) Menghitung Kebutuhan sebulan dan sehari untuk 5 (lima) jenis bahan baku utama pada PT. Martina Berto Tbk. Seperti pada tabel dibawah ini:

Tabel 3

Kebutuhan Bahan Baku Utama Sebulan dan Sehari

Tahun 2015

\begin{tabular}{|c|l|l|r|r|r|}
\hline No. & $\begin{array}{c}\text { Kode } \\
\text { Bahan }\end{array}$ & \multicolumn{1}{|c|}{ Nama Bahan } & $\begin{array}{c}\text { Kebutuhan/ } \\
\text { Tahun }\end{array}$ & \multicolumn{1}{c|}{$\begin{array}{c}\text { Kebutuhan/ } \\
\text { Bulan }\end{array}$} & $\begin{array}{c}\text { Kebutuhan/ } \\
\text { Hari }\end{array}$ \\
\hline$(1)$ & \multicolumn{1}{|c|}{$(2)$} & \multicolumn{1}{c|}{$(3)$} & $14)$ & $(5)=(4) / 12$ & $(6)=(5) / 30$ \\
\hline 1 & KALC01 & ALCOHOL & 81 & 7,0 & 0,5 \\
\hline 2 & KTEX01 & TEXAPON N-70 & 66 & 5,5 & 0,2 \\
\hline 3 & KWHI01 & WHOMOL 15 & 33 & 2,8 & 0,2 \\
\hline 4 & KEUP01 & EUPERLAN PK 771 & 34 & 2,8 & 0,1 \\
\hline 5 & KAXA26 & EDENOR C12-99 MY & 393,9 & 33,6 & 1,1 \\
\hline \multicolumn{6}{|c}{ TO TAL }
\end{tabular}


Bahan baku utama alcohol, kebutuhan bahan baku alcohol dalam setahun sebesar 181 ton, sehingga kebutuhan untuk sebulah sebesar 15.6 ton dan sehari 0.5 ton.

2) Menghitung persediaan maksimum atau maksimum inventory point (MIP). Kebijkan manajemen PT. Martina Berto Tbk. Untuk safety stock ditetapkan 30\% dari kebutuhan bulan berikutnya, jadi berikut ini tabel yang menunjukan hasil peritungan dari persediaan maksimum yang harus diselenggarakan. Dapat disajikan dibawah ini:

Tabel 4

Maksimum Persediaan Bahan Baku Utama

Tahun 2015

\begin{tabular}{|c|c|l|r|r|r|}
\hline No. & $\begin{array}{c}\text { Kode } \\
\text { Bahan }\end{array}$ & \multicolumn{1}{|c|}{ Nama Bahan } & EOQ & $\begin{array}{c}\text { Safety } \\
\text { Stock/Bulan }\end{array}$ & \multicolumn{1}{c|}{ MIP } \\
\hline$(1)$ & $(2)$ & \multicolumn{1}{|c|}{$(3)$} & $(4)$ & $(5)$ & $(6)=(4)+(5)$ \\
\hline 1 & KALC01 & ALCOHOL & 15,6 & 4,5 & 20,1 \\
\hline 2 & KTEX01 & TEXAPON N-70 & 10,4 & 2,0 & 12,5 \\
\hline 3 & KWHI01 & WHOMOL 15 & 9,5 & 1,7 & 11,1 \\
\hline 4 & KEUP01 & EUPERLAN PK 771 & 6,6 & 0,8 & 7,4 \\
\hline 5 & KAXA26 & EDENOR C12-99 MY & 6,8 & 0,9 & 7,6 \\
\hline \multicolumn{7}{|c|}{ TO TA L } & 48,9 & 9,8 & 58,7 \\
\hline
\end{tabular}

Bahan baku utama alcohol, dengan pembelian yang paling ekonomis (EOQ) sebesar 15.6 ton dan safety stock sebesar 4.5 ton, maka persediaan maksimum yang harus diselenggarakan sebesar 20.1 ton.

3) Menghitung Reorder Point yaitu menunjukkan tingkat persediaan bahan baku, dimana perusahaan harus memesan kembali.

Tabel 5

Titik Pemesanan Kembali Bahan Baku Utama Tahun 2015

\begin{tabular}{|c|c|c|c|c|c|c|}
\hline No. & $\begin{array}{l}\text { Kode } \\
\text { Bahan }\end{array}$ & Nama Bahan & $\begin{array}{c}\text { Kebutuhan } \\
\text { / Bulan }\end{array}$ & LT & PLT & ROP \\
\hline (1) & (2) & (3) & (4) & (5) & (6) & $(7)=(4)-(6)$ \\
\hline 1 & KALCO1 & ALCOHOL & 15,6 & 3 & 1,6 & 14,02 \\
\hline 2 & KTEX01 & TEXAPON N-70 & 7,0 & 5 & 1,2 & 5,81 \\
\hline 3 & KWHIO1 & WHOMOL 15 & 5,5 & 5 & 0,9 & 4,60 \\
\hline 4 & KEUP01 & EUPERLAN PK 771 & 2,8 & 5 & 0,5 & 2,30 \\
\hline 5 & KAXA26 & EDENOR C12-99 MY & 2,8 & 5 & 0,5 & 2,35 \\
\hline \multicolumn{3}{|c|}{ TOTAL } & 33,6 & & 4,6 & 29,1 \\
\hline
\end{tabular}

Kebutuhan bahan baku alcohol dalam tiap bulannya adalah sebesar 15.6 ton, dan jumlah penggunaan masa tenggang waktu sebesar 1.6 ton. Jadi apabila jumlah persediaan sudah mencapai titik 14 ton, maka perusahaan harus segera melakukan pemesanan kembali. 


\section{Perbandingan Antara Kebijakan Perusahaan dengan Metode EQO}

Hasil kebijakan perhitungan dengan menggunakan kebijakan perusahaan dan menggunakan EOQ telah diketahui, sehingga dapat dibandingkan untuk memperoleh hasil yang efisien. Perbandingan kebijakan perusahaan dengan hasil penelitian dengan EOQ sebagai berikut :

Bahan Baku Utama Alcohol.

Tabel 6

Perbandingan EOQ Bahan Baku Alcohol

\begin{tabular}{|c|l|r|r|}
\hline No. & \multicolumn{1}{|c|}{ Keterangan } & \multicolumn{1}{c|}{ ACTUAL } & \multicolumn{1}{c|}{ EOQ } \\
\hline$(1)$ & Frekuensi Pembelian Bahan (FPB) & 180 & 12 \\
\hline$(2)$ & Kebutuhan Setahun (RUFA) & 5,0 & 180 \\
\hline$(3)$ & Kuantitas Beli Per Order = (2) / (1) & 11.250 .000 & 11.250 .000 \\
\hline$(4)$ & Cost Per Unit (CPU) & 56.250 .002 & 175.251 .223 \\
\hline$(5)$ & Total Harga Faktur Per Order = (3) x (4) & 28.125 .001 & 87.625 .612 \\
\hline$(6)$ & Rata-Rata Nilai Persediaan = (5)/2 & 1.012 .500 .027 & 1.012 .500 .027 \\
\hline$(7)$ & Harga Beli Setahun = (1) x (5) & 9.857 .143 & 3.163 .826 \\
\hline$(8)$ & Ordering Cost (OC) $=(1) \times$ CPO & 1.015 .486 & 3.163 .826 \\
\hline$(9)$ & Carrying Cost (CC) $=(6) \times$ CCP & 1.023 .372 .656 & 1.018 .827 .678 \\
\hline$(10)$ & Total Cost $=(7)+(8)+(9)$ & & \\
\hline
\end{tabular}

Berdasarkan tabel di di atas bahwa total biaya persediaan yang dikeluarkan sesuai dengan kebijakan manajemen adalah sebesar Rp. 1.023.372.656, sedangkan dengan menggunakan metode EOQ adalah sebesar Rp. 1.018.827.678 sehingga jika menggunakan EOQ perusahaan akan lebih efisien biaya sebesar Rp. 4.544.978.

Total perbandingan biaya untuk 5 (lima) jenis bahan baku utama, jika perusahaan menggunakan metode EOQ adalah sebesar Rp. 7.780.094 selama setahun.

\section{SIMPULAN DAN SARAN}

\section{Simpulan}

1) Berdasarkan dari kebijakan manajemen PT.Martina Berto Tbk. Untuk persediaan pengaman (safety stock) ditetapkan sebsar 30\% dari kebutuhan bulan beikut nya

2) Perbandingan pembelian dan total biaya persediaan perusahaan tanpa EOQ dan dengan metode EOQ Total biaya yang dikeluarkan perusahaan untuk pemesanan 5 (lima) jenis bahan baku utama dalam waktu satu tahun adalah Rp. 3.716.747.821 sedangkan apabila perusahaan menggunakan metode EOQ total biaya persediaan sebesar Rp. 3.708.967.727. Sehingga perusahaan dapat menghemat biaya persediaan sebesar Rp. 7.780 .094 untuk 5 (lima) jenis bahan baku utama saja, belum jumlah penghematan untuk bahan baku lainnya.

3) Dalam melaksanakan pembelian bahan baku, perusahaan harus selalu memperhatikan persediaan yang masih ada.

\section{Saran}

1) Sebaiknya perusahaan mempertimbangkan penggunaan metode Economic Order Quantity (EOQ) dalam kebijakan pengadaan bahan baku 
2) Kebijakan PT. Martina Berto Tbk. Dalam menetukan safety stock sebesar $30 \%$ dari kebutuhan bulan berikutnya.

\section{DAFTAR REFERENSI}

Adisaputro, Gunawan. 2014. Anggaran Perusahaan 1. Edisi 2. BPFE.UGM Yogyakarta

Ahyari, Agus. 1992. Manajemen Produksi . Edisi 4. BPFE UGM. Yogyakarta.

Ahyari, Agus. 2003. Manajemen Produksi Perencanaan Sistem Produksi . Edisi 1. BPFE UGM. Yogyakarta

Alwi, Syafaruddin. 1994. Alat-Alat Analisis dalam Pembelanjaan. Edisi Revisi.Andi Offset.Yogyakarta

Arif, Suadi. 2000. Akuntansi Biaya. BP STIE YKPN. Yogyakarta

Assauri. 1999. Manajemen Produksi dan Operasi, Edisi Revisi, Lembaga Penerbit Fakultas Ekonomi Universitas Indonesia, Jakarta

Carter, Usry. 2009. Akuntansi II Edisi 13 . Salemba 4. Jakarta

Carter, William K. 2009. Akuntansi Biaya Buku 2 Edisi 14. Salemba 4. Jakarta

Dwa Prihasdi, Rahardyan 2012. Efisiensi Metode Economical Order Quantity (EOQ) Dalam Pengambilan Keputusan Pembelian Bahan Baku Dan Pengaruhnya Terhadap Total Biaya Pembelian Pada PT Amitex (Amanah Mitra Industri) Buaran Kabupaten Pekalongan. Universitas Diponegoro. Semarang

Dunia, Firdaus Ahmad dan Wasilah Abdullah. 2009. Akuntansi Biaya Edisi 2. Salemba 4. Jakarta

Dunia, Firdaus Ahmad dan Wasilah Abdullah. 2012. Akuntansi Biaya Edisi 4. Salemba 4. Jakarta

Freddy R. 1989. Statistik Diskriptif. Biro Pusat statistik. Surakarta

Gitosudarmo, Indriyo. 2002. Managemen Keuangan. Edisi keempat. BPFE. Yogyakarta

Gonzalez, Jose L. dan Daniel Gonzalez. 2010. Analysis of an Economic Order Quantity and Reorder Point Invetory Control Model for Company XYZ. California Politechnic State University

Goodwin, Harold Chukwuemeka and Onwurah, Uchendu Onwusoronye. 2013. Inventory Management Pivotal in Effective and Efficient. Nnamdi Azikiwe Unversity. Nigeria 
Handoko, Hani T. 2000. Dasar-dasar Manajemen Produksi dan Operasi. BPFE. Yogyakarta

Hansen, Don R dan Mowen, Maryane M. 2009. Akuntansi Manajerial Diterjemahkan oleh Denny Amos Wari. Edisi 8. Salemba 4. Jakarta

Harahap, Syaparudin. 2008. Manajemen Operasi. Edisi Ketiga. PT. Grasindo. Jakarta

Hasnan, Suad. 1993. Pembelanjaan Perusahaan (Dasar-dasar Manajemen Keuangan), Edisi Keempat, Liberty, Yogyakarta

Herjanto, Eddy. 1999. Manajemen Produksi dan Operasi, Edisi Kedua, PT Gramedia Widiasarana Indonesia, Jakarta

Martono dan Agus Hardjito. 2008. Manajemen Keuangan Edisi Pertama, Cetakan Ketujuh. Penerbit Ekonesia. Yogyakarta

Mulyadi. 2005. Akuntansi Biaya. Edisi 5. Aditya Media. Yogyakarta

Mursyidi. 2008. Akuntansi Biaya. Penerbit : Refika Aditama. Bandung

Nasution, Arman Hakim. 2003. Perencanaan dan Pengendalian Produksi, Edisi Pertama, Guna Widya, Surabaya

Oktaviani, Dwi Elida. 2014. Evaluasi Perhitungan Biaya Persediaan Bahan Baku Dengan Menggunakan Metode Economic Order Quantity (EOQ) Pada PT Indolacto. Sekolah Tinggi Ilmu Ekonomi Indonesia. Jakarta

Reksohadiprojo, Sukanto dan Gitosudarmo, Indriyo. 1993. Manajemen Produksi dan Operasi. BPFE. Yogyakarta

Render, Barry; Heizer, Jay. 2005. Manajemen Operasi. Edisi Ketujuh. Salemba Empat . Jakarta

Riyanto, Bambang. 2010. Dasar-Dasar Pembelanjaan Perusahaan Edisi 4. BPFE. Yogyakarta.

Saputro, Adi dan Marwan, Asri . 1996. Anggaran Perusahaan 1. Edisi Ketiga. BPFE UGM. Yogyakarta

Sariyanti, Riska. 2013. Tinjauan Penerapan Just In Time Sebagai Pengendalian Persediaan Pada PT. Putra Bhakti Mulia. Sekolah Tinggi Ilmu Ekonomi Indonesia. Jakarta

Surnedi, Yusep. 2010. Analisis Manajemen Persediaan Dengan Metode EOQ Pada Optimalisasi Persediaan Bahan Baku Kain Di PT New Suburtex. Universitas Sebelas Maret. Surakarta

Supriyono. 1999. Akuntansi Biaya. Buku 1 Edisi 2. BPFE.UGM Yogyakarta 